\title{
Empreendedor e independente: um novo jornalismo digital com narrativas de impacto
}

\author{
Carolina Rodrigues Oliveira ${ }^{1}$ \\ Marcelo Marques Araújo²
}

\section{RESUMO:}

Este artigo é o resumo da monografia que descreve de que forma o jornalismo empreendedor e o jornalismo independente se unem no desenvolvimento de startups jornalísticas (BRIGGS, 2012; COSTA, 2014; OLIVEIRA; STIPP, 2015; RAMOS; SPINELLI, 2015) e como três estratégias específicas de branding contribuem na construção de uma marca nestes empreendimentos inovadores (AAKER, 2015; BEDENDO, 2015). A partir destes conceitos abordados no referencial teórico, a pesquisa descreve e analisa, por meio do método de análise de conteúdo (GIL, 2008), os diferenciais construídos na plataforma BRIO Stories. Os resultados mostram as conquistas e os desafios desse novo jornalismo digital com narrativas aprofundadas e de impacto.

PALAVRAS-CHAVE: jornalismo empreendedor; jornalismo independente; startups de jornalismo; estratégias de branding; narrativas de impacto.

\begin{abstract}
:
This paper is the abstract of the monograph describing how entrepreneurial journalism and independent journalism are joined in the development of journalistic startups (BRIGGS, 2012, COSTA, 2014, OLIVEIRA, STIPP, 2015, RAMOS, SPINELLI, 2015) and how three specific branding strategies contribute to construct a brand in these innovative ventures (AAKER, 2015; BEDENDO, 2015). Based on these theoretical concepts, the research describes and analyzes, through the content analysis method (GIL, 2008), the differences built on the BRIO Stories platform. The results show the achievements and challenges of this new digital journalism with in-depth and impact narratives.
\end{abstract}

KEYWORDS: entrepreneurial journalim; independent journalism; journalistic startups; branding strategies; impact narratives.

\section{INTRODUÇÃO}

O presente artigo é a síntese do trabalho de conclusão de curso de mesmo título, com o objetivo de mostrar as pesquisas e análises desenvolvidas no decorrer de 2016. A análise

\footnotetext{
${ }^{1}$ Aluna do Curso de Comunicação Social - Jornalismo, da Universidade Federal de Uberlândia. Email: carolina_r.oliveira@hotmail.com

2 Professor do Programa de Mestrado Profissional em Tecnologias, Comunicação e Educação. Orientador. Doutor. Pesquisador nas áreas de Branding, Comunicação Empresarial e Marketing. Email: marcelo.araujo@ufu.br
} 
principal se dá em torno do BRIO Stories ${ }^{3}$, uma plataforma multimídia de jornalismo independente e empreendedor, especializado em grandes reportagens e novos formatos narrativos.

A plataforma é um modelo empreendedor e inovador do fazer jornalístico. Com a revolução tecnológica e a crescente inovação, o jornalismo tem se apropriado do digital para reinventar maneiras de contar histórias.

Empreender não é uma ação nova, mas, atualmente, o assunto está sendo mais discutido e pesquisado. Além disso, tem possibilitado iniciativas inovadoras e independentes dentro de áreas que ainda se mantém presas a um padrão, como o jornalismo.

O empreendedorismo inovador no jornalismo tem relevância para a área pois dá suporte para a busca de novos caminhos, novas abordagens, novos públicos. E, tão importante quanto, os cursos de comunicação social, especificamente com habilitação em jornalismo, precisam mostrar e incentivar o empreendedorismo dentro da área.

Outro aspecto relevante é a crescente inovação em meios digitais, que possibilitam uma narrativa multimidiática. É necessário estudar o formato e discurso destas novas narrativas e como elas contribuem para o diferencial do material jornalístico.

Jornalismo empreendedor, principalmente no meio digital, e jornalismo independente são assuntos que devem ser aprofundados na universidade. Quais são as principais características destes dois campos? Quais são as diferenças entre eles? Como eles se unem na construção de um novo jornalismo, como o construído pelo BRIO Stories?

O BRIO é uma iniciativa que incita a reflexão sobre os novos caminhos que o jornalismo deve tomar para sobreviver com mais intensidade, despertando novos sentidos e emoções em seu público. A plataforma tem características marcantes: as histórias aprofundadas, a narrativa multimídia, o caráter independente e empreendedor.

De que maneira os jornalistas, responsáveis pela produção do BRIO, pensaram e pensam a plataforma? Como eles pensam seus leitores e, consequentemente, suas histórias? Quais são as características que marcam suas narrativas?

A partir das respostas aos questionamentos levantados, o objetivo geral da pesquisa foi descrever e analisar os diferenciais do modelo de jornalismo construído na plataforma BRIO Stories. Para isso, as etapas de desenvolvimento foram: a descrição de características

\footnotetext{
${ }^{3}$ A plataforma BRIO está disponível em: <https://medium.com/brio-stories $>$.
} 
intrínsecas ao jornalismo empreendedor e jornalismo independente em plataformas digitais e a análise de como elas se unem no desenvolvimento de startups de jornalismo que estão em busca de modelos de negócios sustentáveis; e, a análise de três estratégias de branding que marcam novos empreendimentos a curto e médio prazos.

O capítulo a seguir apresenta a revisão bibliográfica sobre jornalismo empreendedor e jornalismo independente em plataformas digitais, suas diferenças e estratégias, e como elas se relacionam para a projeção de um novo caminho para o jornalismo. Também aborda teoricamente sobre mercado e, posteriormente, faz uma descrição de três estratégias de branding: posicionamento, tom de voz e pontos de diferença. Estes estudos teóricos permitem uma análise fundamentada no contexto da marca BRIO.

Em seguida, o capítulo três traz a análise sobre o BRIO Stories. Por meio de pesquisa documental, especificamente com a análise de conteúdo, mostra o que é a plataforma, sobre o que fala, para quem e como fala, e analisa como as características assinaladas na fundamentação teórica se aplicam a ela. Responde de que forma o BRIO Stories se diferencia na construção de um produto jornalístico empreendedor, independente, inovador e com narrativas de impacto.

As considerações finais retomam as análises gerais em relação à pesquisa e às contribuições mais relevantes para a área. De modo geral, este trabalho pode contribuir para ampliar a visão de futuros jornalistas empreendedores e independentes, e despertar um novo sentimento em relação ao fazer jornalístico, com narrativas envolventes, sensíveis e aprofundadas. Estes sentimentos, tão caros e importantes para um jornalismo de qualidade, precisam ser recuperados em uma produção empreendedora e, principalmente, inovadora.

\section{REVISÃO BIBLIOGRÁFICA}

Antes de qualquer coisa, é fato que a internet e as novas tecnologias da informação e comunicação proporcionaram mudanças significativas no mercado de trabalho; e, consequentemente, na profissão jornalística. Elas mudaram e continuam alterando a sociedade, em aspectos gerais, o jornalismo e o jornalista, em específicos.

O jornalismo que acontece diretamente na internet é chamado jornalismo digital, ao contrário daquele que apenas transpõe os conteúdos da mídia tradicional para a web, sendo chamado de jornalismo on-line (FERRARI, 2008). Então, o jornalismo digital é um caminho 
empreendedor no fazer jornalístico.

Não dá para dissociar tudo que já foi feito anteriormente no âmbito da comunicação, então, mesmo que esse digital se sobreponha ao analógico, este influencia aquele. Mas "a questão é colocar essa influência num patamar que abra espaço para o novo, no qual copiar apenas o que já existe não seja o que se espera do que está se formando agora" (JÚNIOR; ALVES, 2010, p. 28).

Conforme Júnior; Alves (2010), é preciso pensar este novo contexto digital e tudo que for criado nele de forma diferente, levando a novos resultados. Com a atual ênfase na noção de empreendedorismo, há mais apoio às novas ideias que vêm surgindo e modificando o ambiente de trabalho; isso não seria diferente no campo jornalístico.

Briggs (2012) afirma que a internet e os novos empreendimentos que surgem a partir dela quebraram as regras ao romper com o monopólio da informação. A indústria jornalística passa por um "momento disruptivo"4, nas palavras de Costa (2014, p. 61).

Aquele jeito antigo de produzir informação, cujo monopólio da distribuição pertencia a uma indústria chamada jornalística, mudou. Ela agora pode ser produzida e distribuída pelas mãos de qualquer um [...].

Acabou-se a era industrial do jornalismo, fruto da disrupção no mercado da informação provocada pelo avanço tecnológico que permitiu a sociedade em rede (COSTA, 2014, p. 63).

Já que qualquer pessoa produz e distribui notícia, o jornalismo precisa de fato se reconfigurar. Ele não deixa de ser importante, apenas precisa mudar sua maneira de atuar (COSTA, 2014). Então, esse é o momento de empreender, inovar e testar novos modelos de negócio e, principalmente, de conteúdo.

Segundo Chiavenato (2007, p. 3, 22), empreendedor é uma palavra que vem do francês entrepreneur, e quer dizer "aquele que assume riscos e começa algo novo" e empreendedorismo é "o processo de criação de algo novo, que tenha valor e seja valorizado pelo mercado".

$\mathrm{Na}$ atual conjuntura tecnológica, mercadológica e econômica, muitos jornalistas veem no empreendedorismo uma motivação para estabelecer projetos pessoais e independentes. Demissões, incompatibilidade com a homogeneização da produção e insatisfação com o

\footnotetext{
${ }^{4}$ Disrupção é um conceito utilizado pelo professor Clayton Christensen. "A palavra vem do latim 'disruptio', que significa espedaçar, romper, destruir. Tem sido muito usada para definir a interrupção do curso normal de algum processo, principalmente em tempos de constantes mudanças tecnológicas” (COSTA, 2014, p. 61).
} 
monopólio da notícia são alguns motivos que impulsionam a criação independente (RAMOS; SPINELLI, 2015, p. 116).

De forma geral, o jornalista empreendedor "não produz seus conteúdos para vendê-los a um terceiro para difusão, mas para ele mesmo divulgá-los e valorizá-los. [...] as lógicas que guiam sua ação são, ao mesmo tempo, as do jornalista e a do empresário da mídia" (CARBASSE, 2015, p. 271). O jornalismo empreendedor está diretamente ligado a um modelo de negócios voltado à sustentabilidade de um produto jornalístico, inovador ou não.

Ser empreendedor não é sinônimo de ser inovador. Levando em consideração a conceituação de Briggs (2012, p. 114, tradução nossa), "inovação é invenção", existem jornalistas que empreendem na criação de um novo meio de comunicação, sem necessariamente inovar em produtos, plano de negócios, conteúdos, entre inúmeras possibilidades.

Mas esta era do digital é uma grande oportunidade para jornalistas empreendedores não reproduzirem modelos do passado. Com a internet, muitas organizações independentes transformaram ideias em negócios de sucesso dentro do campo jornalístico, produzindo conteúdos de qualidade para públicos específicos (BRIGGS, 2012).

Essas organizações independentes que têm surgido no jornalismo são uma vertente no jornalismo empreendedor em busca de outros sentidos ao fazer jornalístico. Dentro destas organizações e deste ambiente digital e empreendedor, surge, de fato, o jornalismo independente. Este "atua como um laboratório de jornalismo. Sem compromissos com ideologias e hierarquias, ele reinventa modos de narrar, de recepção e até mesmo o modo de se fazer jornalismo" (OLIVEIRA; STIPP, 2015, p. 14).

Jornalistas independentes têm mais liberdade de escolher temas, prazos, narrativas, além de investir mais no aprofundamento e humanização das histórias. Eles são personagens “disruptivos" no fazer jornalísticos, já que produzem conteúdos de maneira livre, sem a figura do editor nos moldes conhecidos na cultura tradicional.

Mas também jornalismo independente não é necessariamente jornalismo inovador, podendo seguir o mesmo padrão; apesar deste não ser sustentável como antes, o que justifica, em parte, a demanda por novas linguagens, formatos e produções. A internet abre várias possibilidades para soluções inovadoras dentro do jornalismo, além de trazer o apoio

\footnotetext{
${ }^{5}$ Do original: "Innovation is invention" (BRIGGS, 2012, p. 114).
} 
necessário para facilitar o trabalho independente, já que reduz grande parte dos custos.

Explorar as possibilidades que a internet propõe é um caminho para uma produção independente inovadora, que faça sentido para o público, além de indicar novos formatos para um jornalismo mais aprofundado, engajado e com mais propósito.

\section{Quadro 1 - Características de jornalismo empreendedor e jornalismo independente}

\begin{tabular}{|c|c|}
\hline Jornalismo empreendedor & Jornalismo independente \\
\hline Voltado para o mercado & Flexibilidade \\
\hline Visão empresarial & Independência na produção \\
\hline Direcionado para administração & Liberdade narrativa \\
\hline Modelo de negócio & Modelo de prática jornalística \\
\hline
\end{tabular}

Fonte: A autora (2016)

Ao contrário do jornalismo empreendedor, que está voltado para um plano de negócios, o jornalismo independente se refere a um modelo de prática jornalística. A confluência entre os dois em uma construção inovadora propiciam uma nova força ao fazer jornalístico, pluralizada e desvinculada dos grandes grupos que monopolizam a mídia; é mais um processo de "disrupção" neste ambiente que precisa se renovar continuamente para sobreviver.

Para sustentar-se no meio digital, a indústria jornalística precisa entender as novas circunstâncias para se recriar. Conhecer o mercado, conectar-se com o público e observar as novas formas de consumo são os primeiros passos para superar os desafios que o novo contexto sugere (COSTA, 2014).

O que as pessoas estão procurando de diferente no jornalismo, principalmente na internet? Briggs (2012, p. 15, tradução nossa) afirma que "audiências online buscam imediatismo, interatividade, personalização e, mais recentemente, conexão social. Notícias tradicionais, mostradas como aparecem no jornal da manhã, parecem genéricas e sem vida em comparação"6.

\footnotetext{
${ }^{6}$ Tradução do original: "Online audiences expect immediacy, interactivity, customization, personalization and, more recently, social connection. Traditional news stories, reprinted online as they appeared in the morning newspaper, looked generic and lifeless in comparison" (BRIGGS, 2012, p. 15).
} 
A influência da internet sobre a sociedade, o mercado de trabalho e o jornalismo recai, consequentemente, no mercado de consumo. O modo tradicional de fazer jornalismo não faz tanto sentido neste contexto. O mundo está digitalizando e o jornalismo precisa seguir este fluxo para sobreviver.

De acordo com Abiahy (2005), os indivíduos demandam por uma personalização, ou especialização no caso de informações jornalísticas. As pessoas precisam de coisas com as quais se identifiquem, para se orientarem e, até mesmo, controlarem a variedade de conteúdos que têm acesso todos os dias.

Essa especialização se dá tanto no conteúdo quanto no receptor. Não são somente as temáticas que definem os nichos de mercado no ambiente jornalístico, por isso a importância de inovar também na linguagem e abordagem produzidas (ABIAHY, 2005). Este nicho pode estar procurando novos formatos narrativos, uma linguagem criativa, independente do tema.

Tudo isso deve ser levado em consideração para uma nova produção independente e empreendedora. Além disso, é preciso uma conexão social entre quem oferta e quem busca, e entre todos que, de certa forma, se beneficiam do que é produzido. As startups são resultados dessa nova dinâmica.

As reinvenções e inovações que têm ocorrido no jornalismo, principalmente no contexto digital, são chamadas startups de jornalismo. Esses novos projetos estão dando outras configurações ao jornalismo que se produz na web (BRIGGS, 2012).

Startups são culturas de empreendedores multifuncionais em iniciativas inovadoras de extremo risco e que possuem um modelo de negócio sustentável, escalável, adaptável e enxuto (RIES, 2012).

Um negócio sustentável é aquele que consegue se sustentar e produzir retorno financeiro. Escalável é a capacidade de alcançar e impactar muitas pessoas com o mesmo produto dentro e fora do nicho de mercado. Adaptável é um empreendimento que, por ter muita interação com o público, possibilita mudanças no processo de construção do produto a partir do feedback daqueles que serão os principais consumidores da nova criação. Enxuto é um método para validar e testar a eficiência do produto de forma mais rápida, por meio de um Produto Mínimo Viável ${ }^{7}$ (RIES, 2012).

As características que descrevem as startups podem ser utilizadas como ações

\footnotetext{
${ }^{7}$ Produto Mínimo Viável é uma metodologia rápida que cria uma versão simplificada para testar e validar se as pessoas realmente precisam da startup que está sendo desenvolvida (RIES, 2012).
} 
estratégicas em plataformas digitais. E, como afirma Briggs (2012, p. 20, tradução nossa) "ao abraçar o risco [...] e formar um modelo de negócios nativo ao novo ecossistema de informação digital, startups [...] podem, mais rapidamente, encontrar inovação nos negócios, onde empresas tradicionais de notícias não conseguiram".

No jornalismo, as startups trazem inovação no meio, na técnica e/ou no conteúdo que gera. Essas inovações são respostas ao novo mercado, mais segmentado e com desejo de originalidade e pluralidade. O jornalismo empreendedor, independente e inovador está em constante construção, se moldando para alcançar e atender seu público-alvo.

Ramos; Spinelli (2015) afirmam que o grande desafio é tornar essas empresas digitais sustentáveis. É preciso gerar valor sobre a forma e o conteúdo produzidos. Para sobreviver, “[...] o modelo de negócio da imprensa também precisa se digitalizar. [...] não há como 'analogizar' a comunicação em rede" (COSTA, 2014, p. 60). E, nesse caso, Costa (2014) propõe um caminho com três combinações: publicidade, paywalls e serviços de valor agregado.

A publicidade precisa ter escala, ser segmentada ou estar de acordo com os anseios do público e trabalhar com custo por mil (CPM) ${ }^{9}$. Os paywalls são pagamentos mensais ou anuais para o acesso ao conteúdo produzido. E serviços de valor agregado são serviços e produtos secundários que são comercializados além do conteúdo.

O negócio do jornalismo não é mais somente a informação, e sim um negócio de serviços em comunicação (COSTA, 2014). Nem sempre o conteúdo é suficiente para sustentar um negócio jornalístico independente.

Mas, como enfatiza Costa (2014), “este modelo só vingará [...] se as receitas estiverem servindo a uma plataforma de conteúdo adequada ao novo ambiente, vocacionada para o compartilhamento e embasada para a prestação de serviço, ou de serviços" (COSTA, 2014, p. 110-111). De qualquer forma, esse é o momento para testar todas as possibilidades, fazer escolhas que podem ou não funcionar, aprender com os erros e desenhar diferentes formas e caminhos (COSTA, 2014).

Outras possibilidades empreendedoras para conseguir sustentabilidade estão em novas

\footnotetext{
${ }^{8}$ Tradução do original: "By embracing risk [...] and forming a business model that is native to the new digital information ecosystem, startups $[\ldots]$ can more quickly find business innovation where traditional news companies did not" (BRIGGS, 2012, p. 20).

${ }^{9}$ CPM é uma estratégia publicitária, no qual o anunciante paga a cada mil visualizações da publicidade em determinada página (COSTA, 2014).
} 
maneiras de unir publicidade e jornalismo, com o brand content e o branded content. Esta se refere à apropriação de uma marca anunciante de conteúdos já existentes para se propagar e aquela à conteúdos produzidos pela própria marca anunciante (ZOZZOLI, 2010).

Esses conteúdos de marca não possuem o cunho comercial da publicidade tradicional e buscam se aproximar dos valores de seu público ao "abordar conceitos, despertar sentimentos, atrair para ações que correspondem aos anseios dos consumidores em potencial, retendo sua atenção com pertinência para obter seu envolvimento e participação" (ZOZZOLI, 2010, p. 24).

Os caminhos propostos devem ser levados em consideração, mas com a crescente inovação digital novas formas de sustentabilidade são criadas e testadas recorrentemente. Então, a inovação jornalística não envolve somente o formato e conteúdo, mas também, e tão importante quanto, o modelo de negócio.

\subsection{Características marca(ntes) para o negócio jornalístico}

Antes de construir um modelo de negócios existe uma força primária que impulsiona o empreendedor: o propósito. Conforme Bedendo (2015, p. 70-72), “o propósito é o porquê de uma empresa fazer as coisas. [...]. O propósito é maior que o produto, pois é ele o que vai ditar o que o produto deve oferecer como benefício, e como ele pode evoluir". É isso que diferencia e dá identidade a cada empreendimento; como demonstra Araújo (2016, p. 10) ao afirmar que "marcas de sucesso possuem uma identidade própria que está ancorada em um propósito definido".

Então, o propósito limita e direciona o empreendimento, interna e externamente, pois ela não pode abarcar todas as pessoas; por isso a importância de um nicho de mercado específico. Consequentemente, ao fazer essa seleção, o propósito demarca o que será feito, o formato da equipe, os modelos de negócio apropriados, as estratégias necessárias, e todas as atividades que fazem um negócio sair do papel.

É a partir do propósito que surge a necessidade de construir um branding em coerência com as finalidades do negócio e o impacto que deseja causar no público-alvo (BEDENDO, 2015). Branding é o termo designado para "gerenciador de marcas". Existem outras definições, mas de forma geral "o papel fundamental é o gerenciamento da marca acerca dos valores agregados, do posicionamento adotado e da percepção que os consumidores possuem 
da mesma" (JÚNIOR, 2015, p. 8).

Segundo Júnior (2015, p. 2), “a palavra marca significa nomear, titular e origina-se do inglês brand" (JÚNIOR, 2015, p. 2). Mas a conceituação vai muito além da nomeação; elas "podem ser definidas como construções simbólicas que nascem de um processo dinâmico de trocas entre agentes sociais e sintetizam valores, atitudes e experiências referentes a determinados produtos, serviços ou organizações" (CARNEIRO, 2011, p. 15).

Marca é algo que sobressai, particulariza e diferencia. Ela possui um "ecossistema” de relacionamento entre os públicos, interno e externo, que estão, direta ou indiretamente, ligados e exercem influência. Conhecendo bem esse público e o contexto que se insere, a marca consegue criar estratégias específicas para inovar (ENDEAVOR, 2014).

Desta forma, como os empreendimentos independentes e inovadores de jornalismo podem impactar seu público-alvo por meio de estratégias de branding? Primeiro, o plano de branding precisa estar de acordo com o plano de negócios do empreendimento (AAKER, 2015) e ambos precisam de estratégias para curto, médio e longo prazos. A consolidação de uma marca requer tempo, mas algumas características conseguem impactar no começo do empreendimento se forem bem desenvolvidas e fundamentadas no propósito.

Três características essenciais para serem pensadas a princípio são: posicionamento, tom de voz e pontos de diferença. Existem muitas outras características que devem ser analisadas e desenvolvidas para uma marca bem-sucedida, mas, para a finalidade deste trabalho, optou-se por trabalhar com as três de mais impacto a curto e médio prazo.

A construção de uma marca requer um posicionamento. Se o empreendimento for incipiente, é preciso deixar a posição ainda mais evidente.

O conceito de posicionamento fala sobre uma oferta distinta (que possui um diferencial em relação à concorrência) e valorizada (que seja atraente para um público-alvo). [...]. É importante formalizar essa relação entre o públicoalvo, os concorrentes e o diferencial em uma frase curta e de fácil entendimento. [...]

Para (um público-alvo), a marca (X) oferece (diferenciais) para que os seus consumidores sintam-se (beneficios emocionais) (BEDENDO, 2015, p. 60, grifo do autor).

O posicionamento pode ser considerado "um guia de comunicação de curto prazo que [...] enfatiza os elementos de visão de marca que serão atraentes e que agora têm credibilidade e cuja concretização é realista" (AAKER, 2015, p. 27). Dessa forma, ele é importante porque 
se molda a partir das características mais marcantes e inerentes ao empreendimento, além de ser voltado ao que é mais importante para o mercado-alvo.

O posicionamento tem a ver com uma comunicação externa, referente a alguma categoria de diferencial da marca e direcionada para o público. O método e a mensagem podem mudar no decorrer do tempo, mas tudo que for comunicado precisa ser objetivo e realizável, pois pode ser considerado uma promessa feita pela marca (AAKER, 2015).

Com um posicionamento bem definido, a marca precisa saber comunicá-lo ao seu público. Essa comunicação é verbal e visual, mas ambas são movidas pelo "tom de voz" que a marca adota; "o tom de voz da marca é a maneira como a marca se expressa por meio de suas comunicações" (BEDENDO, 2015, p. 83, grifo do autor).

A comunicação dá forma à identidade da marca. Ela a divulga, por isso é importante refletir bem o propósito e o posicionamento; é através da formulação bem executada destas características que é possível desenvolver o "tom de voz” que conduzirá a comunicação entre a marca e seu público (BEDENDO, 2015).

A marca também precisa estar alinhada com o contexto de seu público-alvo para se comunicar com ele de forma eficiente. O tom de voz é uma estratégia para alcançar este público e conquistar reconhecimento.

Somente por meio de um discurso estratégico pode-se atingir a consistência da comunicação, estabelecendo familiaridade e confiança com o público.

O mais importante, porém, é que o tom de voz adotado, tal como as histórias narradas pela marca, reflitam sempre a verdadeira essência da empresa e das pessoas envolvidas. Não é preciso reinventar completamente a linguagem, mas sim identificar e aperfeiçoar uma maneira de usar palavras já existentes na empresa. A essência produz sentidos significativos (ARAÚJO, 2016, p. 14).

Produzir "sentidos significativos" deve ser o objetivo de uma marca ao se comunicar com as pessoas, pois de nada adianta uma afirmação que não faça sentido e que não expresse verdadeiramente o propósito do negócio. Tudo que é falado, é avaliado pelo público de alguma forma.

Então, pensar a marca é visualizar o conjunto de características que representam o negócio e utilizar estratégias de branding para comunicá-las ao público. Quanto mais diferente for esse conjunto, mais notável se torna e é a partir da comunicação que ela se torna reconhecida. 
Ser diferente é um aspecto relevante dentro do propósito que conduz o empreendimento. Conforme Aaker (2015), é preciso inovar, e quanto mais inovador, maior a necessidade de construção de uma marca porque são justamente as diferenças que fazem as marcas serem conhecidas e reconhecidas, além de fidelizarem os clientes.

Segundo Araújo (2016, p. 10), "quando uma marca conhece o seu mercado e tem um propósito, ela tem condição de propor o novo, o inesperado”. Então, as startups de jornalismo precisam buscar essa inovação, para formalizar, caracterizar e marcar um jornalismo de qualidade e responsabilidade social, produzido de forma independente. Essas inovações criam pontos de diferença, e o branding deve se apropriar destes para construir uma marca que atraia e impacte seu público.

Pontos de diferença (PDs) são as associações de marcas fortes, favoráveis e exclusivas [...]. Os PDs são atributos ou benefícios que os consumidores associam fortemente com uma marca, avaliam positivamente e acreditam não poder encontrar com a mesma intensidade em uma marca concorrente (KELLER; MACHADO, 2006 apud JÚNIOR, 2015, p. 6, grifo do autor).

Os pontos de diferença são coisas que uma marca produz de diferente das outras, seja por ser a única a fazer ou por ser a que desenvolve com mais qualidade. Segundo Aaker (2015, p. 68), eles podem ser um "recurso, ingrediente, tecnologia, serviço ou programa".

O recurso é uma vantagem exclusiva muito valorizada pelos clientes; o ingrediente é um elemento marcante que torna o produto mais visado; a tecnologia é uma técnica avançada e inovadora que gera valor e força sobre a marca; serviço é a forma clássica de se diferenciar pois está ligada à funcionalidade do que é desenvolvido; e, o programa serve para ampliar a oferta do produto (AAKER, 2015).

Bedendo (2015) separa esses diferenciais em funcionais, emocionais e de autoexpressão. As diferenças funcionais estão diretamente ligadas à função e utilidade do produto/serviço; as emocionais se referem às sensações das pessoas ao utilizarem a marca; e, as de autoexpressão são simbólicas, pois são apropriadas pelos clientes a fim de mostrarem personalidade para a sociedade.

Mesmo que os autores citados não utilizem as mesmas categorias para separar os diferenciais da marca, ambos frisam a importância em ter um elemento de diferenciação, algo que realmente seja marcante no empreendimento. Independente de classificação teórica, uma marca, neste caso em um empreendimento jornalístico, precisa de uma característica que a 
diferencie das outras e que tenha influência positiva na vida das pessoas.

Por fim, a marca é a comunicação que se constrói a partir de um diferencial, além de ser a materialização do propósito e posicionamento do empreendedor. Bedendo (2015, p. 113) sintetiza isso ao afirmá-la como a alma dos empreendimentos do século atual.

"A marca é a alma do negócio" (BEDENDO, 2015, p. 113) porque, quando bem desenvolvida com propósito, se propaga e vende por si mesma, independente da estratégia de publicidade que use. Isso demonstra como a marca está além de uma nomeação e que, provavelmente, sua principal importância está em gerar impacto na vida das pessoas de alguma forma.

Os empreendimentos inovadores no jornalismo precisam buscar estes recursos de branding para construir projetos de relevância, com conteúdos que marcam e despertam a atenção das pessoas. Novas práticas narrativas em plataformas digitais são apostas para esse novo jornalismo; o BRIO Stories é o exemplo analisado a seguir.

\section{METODOLOGIA}

Enquanto pesquisa documental, que utiliza como fonte de pesquisa documentos que ainda não foram analisados e/ou problematizados - reportagens, cartas, filmes, gravações, fotografias, entre inúmeros - (GIL, 2008), a metodologia utilizada é a análise de conteúdo. Este método pode ser definido como "uma técnica de investigação que, através de uma descrição objetiva, sistemática e quantitativa do conteúdo manifesto das comunicações, tem por finalidade a interpretação destas mesmas comunicações” (BARELSON, 1952, p. 13 apud GIL, 2008, p. 152).

A análise dos documentos se dá em três etapas: pré-análise para organizar e preparar o material; estudo do material para selecionar e fazer o recorte do que realmente será analisado; e, tratamento, dedução e interpretação dos dados coletados (BARDIN, 1977 apud GIL, 2008).

Todos os textos da plataforma BRIO Stories foram lidos para selecionar o que permitiu a análise e interpretação das características da plataforma, o porquê de ela ser considerada startup de jornalismo, como está buscando se tornar um empreendimento sustentável, o modo que utiliza as três estratégias de branding e como se diferencia através da narrativa.

Para analisar o processo de construção do negócio empreendedor e independente do 
BRIO foram retiradas informações de alguns textos, escritos por Breno Costa $(2015 ; 2016)$, co-fundador e editor-executivo do BRIO, e disponibilizadas na página fixada na plataforma Medium. No que se refere às estratégias de branding, a análise foi feita a partir de uma observação das características que são constantes nas narrativas, além da frase que aparece na página inicial da plataforma indicando o posicionamento do BRIO.

\section{BRIO Stories: jornalismo de impacto}

Algumas definições para a palavra brio, segundo o Michaelis Dicionário Brasileiro da Língua Portuguesa (2015), são: "qualidade de quem se comporta com intrepidez diante de riscos e adversidades; coragem, destemor, ousadia [...]. Tendência a ser persistente no que se pretende fazer ou alcançar; determinação, empenho, entusiasmo [...] (MICHAELIS, 2015, s.p.).

Provavelmente, BRIO Stories quis apropriar um pouco de cada uma dessas significações para construir uma plataforma diferente que produz um "jornalismo livre, de qualidade e relevante" (COSTA, 2015, s.p.). Esse pode ser considerado um dos propósitos que conduziram à sua criação e o tom de voz utilizado que dá início à construção da marca BRIO.

Inspirado primeiramente no modelo jornalístico do The Atavist ${ }^{10}$, BRIO é uma plataforma digital multimídia de reportagens em longform, ou longo formato, e aprofundadas em temas de interesse humano, lançada pelos jornalistas Breno Costa, Felipe Seligmam, Fernando Mello, o engenheiro Marc Sangarné e o designer Tomas Silva, em maio de 2015.

Nem sempre um empreendimento de sucesso em um lugar pode ser reproduzido em outro, por inúmeras razões. Isso não é empecilho para se inspirar em ideias inovadoras e testálas, mas é preciso ter percepção para ver a aplicabilidade e, talvez, a necessidade de mudar os planos e desenvolver alternativas. Então, BRIO não se tornou um The Atavist, mas tem conseguido um espaço no mercado, visibilidade enquanto novo caminho para o jornalismo no Brasil e êxito em alguns aspectos que serão pontuados ao longo da análise.

A ideia de criar uma rede de produtores de conteúdo foi inviabilizada, a princípio, e o

\footnotetext{
${ }^{10}$ The Atavist é uma plataforma digital de narrativas jornalísticas de longo formato, com histórias aprofundadas e design inovador, e especialista em storytelling. Além disso é uma rede de produtores de conteúdo e uma ferramenta de publicações (THE ATAVIST, 201?). Mais informações disponíveis em: $<$ https://atavist.com/>.
} 
foco se voltou para o conteúdo de fato, uma narrativa de longo formato publicada por mês. O modelo de negócios proposto era a venda de reportagens, mas, pouco tempo antes do lançamento da plataforma, os fundadores decidiram liberá-las gratuitamente para analisarem as reações do público receptor e construírem uma "audiência relevante".

Assim começaram com a narrativa "A espera”, escrita por Matheus Leitão, contando a busca por quem entregou seus pais, os também jornalistas Míriam Leitão e Marcelo Netto, para a tortura no período da ditadura militar. Esta história iniciou a produção de narrativas aprofundadas e engajadas que são características de destaque do BRIO.

Até dezembro de 2016, BRIO contou 16 histórias. As narrativas são escritas por jornalistas independentes e elas não são especializadas em um tema ou área de conhecimento, e sim no aprofundamento da história e dos fatos, que podem ou não estar em destaque na agenda jornalística. BRIO é um jornalismo especializado em "narrativas de alto impacto" (BRIO, 2015, s.p.), em um discurso inovador voltado para um público específico.

E quem são os leitores destas narrativas? Pessoas com interesse em narrativas de qualidade, engajadas e impactantes; "um público ávido por boas histórias e que não se contenta apenas com posts e tuites" (COSTA, 2015, s.p.).

Inclusive, BRIO tem um posicionamento que sinaliza quem é este leitor: "histórias reais e jornalismo de fôlego para quem gosta de ter assunto" (BRIO, 2015, s.p., grifo nosso). O posicionamento, enquanto estratégia de branding descrito na teoria de Bedendo (2015), revela que BRIO está ancorado na inovação de uma narrativa de impacto (diferencial) voltada para quem gosta de ler (público-alvo) e utiliza destas leituras como fonte de assunto no dia-a-dia (benefícios emocionais). Então ele se posiciona de maneira a oferecer o melhor produto e experiência memorável para o cliente (ENDEAVOR, 2014).

As narrativas do BRIO rompem com os padrões e são "dignas de cinema" (COSTA, 2016, s.p.). São construções jornalísticas independentes e multimídia, com liberdade de linguagem, ilustrações abstratas que despertam emoções, vídeos complementares e explicativos. Possuem um discurso que "traz à tona personagens, fatos, informação, contexto e reflexão em narrativas de alto impacto" (BRIO, 2015, s/p, grifo nosso).

Apesar de serem envolventes, por inúmeros fatores as primeiras histórias tiveram poucas visualizações. Como empreendimento de risco em busca de sustentabilidade, BRIO utilizou dessa constatação, feita nos primeiros quatro meses, para dar início a uma nova fase da plataforma. Esse movimento de mudar os planos iniciais de um empreendimento inovador 
de acordo com o retorno do público é uma das principais características das startups (RIES, 2012). É preciso entender as reações das pessoas, mesmo que nem elas próprias entendam, e utilizá-las em benefício do negócio.

A principal mudança realizada foi, sem dúvidas, o formato de publicação das narrativas. O problema não estava no conteúdo em si, então pensaram na "facilitação da experiência do usuário" (COSTA, 2016, s.p., grifo do autor).

$\mathrm{Na}$ primeira fase do BRIO, as reportagens eram disponibilizadas integralmente, com leitura média de 57 minutos. Na segunda fase, elas foram divididas em atos ou capítulos, publicados em dias diferentes. Uma mudança consideravelmente simples que redefiniu a percepção do público.

Além das narrativas em capítulos, passaram a fazer mais uso das ilustrações, feitas pelo designer, fotógrafo e ilustrador Pedro Matallo. Elas também podem ser consideradas uma estratégia de marca, pois são um diferencial impactante, provocativo e que desperta interesse.

"Sobre a Sede" foi a reportagem que inaugurou o novo formato narrativo do BRIO. Em 21 dias foram mais de 28 mil leitores. E o motivo principal foi somente essa "facilitação" no processo de leitura, além de chamar a atenção porque desperta curiosidade; a pessoa que lê o primeiro ato aguarda a publicação da continuação, como nas séries televisivas.

Neste momento, o foco se voltou para o aperfeiçoamento da narrativa como um todo. Agora a qualidade não estava somente no conteúdo, mas também na forma, e todas essas mudanças se tornaram características marcantes que fazem da marca BRIO um formato narrativo "disruptivo".

O novo formato estava validado, mas ainda assim estavam sem um modelo de negócios realmente sustentável. Até então, todo dinheiro utilizado no desenvolvimento da plataforma e na publicação das reportagens era dos próprios fundadores e de pouco investimento externo. Todos os esforços estavam voltados para a construção da marca BRIO. Mas sem dinheiro nenhuma marca vai para frente.

Então, no período de janeiro a junho de 2016, BRIO ficou sem publicações. Talvez fosse o temido fim, mas em 23 de junho retornou com a publicação da narrativa "Os pastores nos campos de pedra", escrito pelo jornalista Aiuri Rebello, e um texto em tom pessimista e confiante, ao mesmo tempo, pedindo desculpas e justificando a pausa de cinco meses. $\mathrm{O}$ principal motivo: “[...] qualidade não é sinônimo de eficácia financeira. Essa percepção 
externa de qualidade não tem sido suficiente para garantir uma operação sustentável" (COSTA, 2016, s.p.).

Neste texto, o co-fundador do BRIO aponta para o risco de parar as produções narrativas em longo formato até o final de 2016 - tempo para publicar as cinco reportagens que já estão prontas ou em processo de finalização - e menciona o desenvolvimento de um novo produto, sinalizando que não era o fim da marca BRIO.

BRIO é um negócio incerto, como qualquer startup. Está em um ambiente digital que é totalmente inconstante; o que é interessante em um dia, pode ser facilmente esquecido no outro. Tudo que é desenvolvido, é testado e validado pelo público, e é a partir do retorno deste que a plataforma vai mudando. E mesmo assim corre o risco de não crescer e gerar retorno financeiro.

Então, no decorrer da produção desta pesquisa, em 12 de setembro de 2016, o produto que estava sendo desenvolvido foi lançado: BRIO Hunter"11, "uma plataforma que ajuda jornalistas a tirar do papel ideias de projetos próprios, oferece treinamentos em áreas específicas e os ajuda no refinamento de pautas e na busca de espaço para publicá-las" (COSTA, 2016, s.p., grifo do autor).

BRIO Hunter não se trata de um curso de jornalismo. É uma plataforma digital de valorização do processo jornalístico e de capacitação empreendedora do jornalista, que funciona com vídeo-aulas, tutoriais, webinários, e outras ferramentas online.

BRIO Hunter pode ser considerado um produto de serviço agregado e é um novo modelo de negócios com possibilidade de retorno financeiro. BRIO não estava conseguindo sustentabilidade porque não vendia, então, com o serviço do BRIO Hunter, ele começa a criar chances reais de sobreviver e construir a marca BRIO com impacto e voltada para o público que "gosta de ter assunto".

No último texto publicado na plataforma BRIO, Costa $(2016$, s.p.) prenuncia o futuro das narrativas em longo formato depois da publicação das duas últimas reportagens. A ideia é “criar uma espécie de 'Spotlight' brasileira”. Reunir talentos descobertos pelo Hunter e "montar um time forte, com aptidões variadas, para acompanhar de perto e constantemente os temas do momento e trazer novidades, mas no melhor estilo de BRIO de fazer jornalismo".

Se essa junção entre BRIO Stories e BRIO Hunter der resultados, pode-se supor até

\footnotetext{
${ }^{11}$ Plataforma disponível em: <http://briohunter.org/>.
} 
que desenvolvam outros produtos que já eram possibilidades antes do período de crise, "como séries de TV, podcasts e até mesmo filmes" (COSTA, 2015, s.p.). A exemplo da Epic Magazine $^{12}$ que transforma suas longas narrativas em roteiros cinematográficos, seria outra tentativa para sustentar o BRIO Stories.

Outra alternativa de sustentabilidade é a publicidade, mas não nos moldes padrões (COSTA, 2014). É preciso usá-la de forma consciente e responsável. Querendo ou não o jornalismo é um negócio e precisa ser vendido para sobreviver. Isso não significa ser conivente com o atual padrão, em que o jornalismo produzido é "influenciado" por aqueles que pagam pela sua sobrevivência. Este "ser vendido" significa vender um jornalismo de qualidade e buscar meios para que ele sobreviva, entre eles a publicidade.

Sejam quais forem as estratégias, as startups de jornalismo ainda estão buscando um modelo de negócio sustentável, cada uma a seu modo. A busca por sustentabilidade não é necessariamente a busca por lucros; ser sustentável é conseguir retorno financeiro para a sobrevivência do negócio. Muitas startups não visam lucros financeiros, e sim sustentar adequadamente o tipo de jornalismo que produzem, com independência e sem interferência de algo que poderia as prender de alguma forma - por isso o receio com a publicidade. Mas, de forma geral, todas anseiam sobreviver desse novo jornalismo que surge e traz esperança para a área de se sobrepor ao "modo maçante" do padrão que ainda é produzido.

\section{CONSIDERAÇÕES FINAIS}

É possível empreender em um negócio jornalístico inovador, independente e com propósito, clareza e engajamento. A partir de tudo que foi exposto, arrisca-se duas conclusões principais: o novo modelo de jornalismo é digital e possui uma narrativa de impacto, seja pela linguagem que desperta emoções, pelo aprofundamento dos fatos, pelo formato narrativo enfim, uma forma diferente de contar histórias. O novo jornalismo digital precisa ser marcante.

O atual contexto social é digital (BRIGGS, 2012; COSTA, 2014) e o jornalismo tem se apropriado disso para inovar. Essa inovação pode acontecer no formato, no meio, no

\footnotetext{
${ }^{12}$ Epic Magazine é uma plataforma digital de narrativas jornalísticas em longo formato que já vendeu mais de 25 histórias como roteiros cinematográficos para Hollywood (EPIC MAGAZINE, 201?). Mais informações disponíveis em: $<$ http://epicmagazine.com/>.
} 
conteúdo, entre várias possibilidades. A internet propicia e, de certa forma, facilita o empreendimento e a inovação, o que desencadeia o excesso de conteúdo que se tem acesso.

Com esse excesso, as pessoas estão buscando mais conteúdos especializados e o jornalismo tem ousado no desenvolvimento de empreendimentos voltados para nichos de mercado específicos. A análise revela o surgimento de um novo jornalismo, que preza por narrativas mais humanas, para pessoas que querem outras visões de jornalismo.

Pela metodologia da análise de conteúdo, as respostas ao objetivo geral da pesquisa, de descrever e analisar os diferenciais do BRIO Stories, foram essencialmente de um jornalismo empreendedor e independente com o propósito de, além de informar, despertar emoções, engajar, entre inúmeros outros que geram impacto de alguma forma; além de pautar as conversas das pessoas no dia-a-dia, como pontua em seu posicionamento.

Outro aspecto que precisa ser destacado é a importância do branding no negócio jornalístico. Um empreendimento inovador sempre recorre a estratégias de marca, mesmo que instintivamente, para demarcar seus diferenciais. Então, se usado de forma consciente e autêntica, pode potencializar a adesão do público.

Sustentabilidade tem sido o grande desafio. Há a busca por meios que não "vendam" o propósito e os princípios que regem o empreendimento; e isso não se trata de uma situação ilusória. É preciso encarar o jornalismo como um negócio, e, com isso, estudá-lo em conjunto com disciplinas como empreendedorismo, comunicação organizacional, marketing, branding, e todas que abordem, de forma direta ou indireta, o contexto empresarial. O incentivo ao jornalismo empreendedor e, principalmente, inovador deve iniciar na universidade. Um ensino que incentive a problematização teórica em conjunto com práticas inovadoras e desenvolvimento de estratégias de sustentabilidade; a universidade é um ambiente de experimentações que precisa ser mais explorado no campo jornalístico.

Por fim, esta pesquisa aborda alguns poucos conceitos relevantes para entender as startups de jornalismo e como elas unem o jornalismo independente com o empreendedorismo e estratégias de branding em busca de sustentabilidade para negócios inovadores que não visam mais somente o conteúdo, mas um serviço jornalístico com brio.

\section{REFERÊNCIAS}

AAKER, David. On Branding: 20 princípios que decidem o sucesso das marcas. Porto 
Alegre: Bookman, 2015.

ABIAHY, Ana Carolina de Araújo. O jornalismo especializado na sociedade da informação. João Pessoa, Universidade Federal da Paraíba. 2005. Disponível em: http://www.bocc.ubi.pt/pag/abiahyana-jornalismo-especializado.pdf. Acesso em: dezembro de 2012 .

ARAÚJO, Marcelo Marques. Branding e Discurso nas Organizações: objetos em interface dialógica na Comunicação Organizacional. In: XXI Congresso de Ciências da Comunicação na Região Sudeste, 2016, Salto - SP. Anais. Intercom, 2016, p. 1-15. Disponível em: $<$ http://www.portalintercom.org.br/anais/sudeste2016/resumos/R53-1456-1.pdf > . Acesso em: 08 out. 2016.

BEDENDO, Marcos. Branding para empreendedores: ferramentas práticas para criar sua marca potencializando o sucesso do seu negócio. São Paulo: M.books do Brasil Editora Ltda., 2015.

BRIO. Sobre o BRIO. 2015. Disponível em: <https://medium.com/@briostories/sobre-obrio-d39729b943ff\#.oabn3ix07>. Acesso em: 09 mar. 2016.

BRIGGS, Mark. Entrepreneurial Journalim: how to build what's next for news. Los Angeles: Sage, 2012. Kindle Edition.

CARBASSE, Renaud. Tino para os negócios e bom jornalismo?: A figura do jornalista empreendedor nos debates sobre o futuro da profissão. Brazilian Journalism Research, $v$. 11, n. 1, p.262-283, 2015. Disponível em: <https://bjr.sbpjor.org.br/bjr/article/view/591/629>. Acesso em: 11 maio 2016.

CARNEIRO, Levi. Marca corporativa: um universo em expansão. Grupo Troiano de branding, 2011. Disponível em: <http://troianobranding.com/devsite/wpcontent/uploads/2015/09/Marca-corporativa-um-universo-em-expansao-2a-edicao-LeviCarneiro.pdf >. Acesso em: 01 nov. 2016.

COSTA, Breno. A gente tem uma super novidade para te contar. Set. 2016. Disponível em: $<$ https://medium.com/brio-stories/a-gente-tem-uma-super-novidade-pra-te-contarfd3f34fdaf32\#.ect548r40>. Acesso em: 7 out. 2016.

. É preciso valorizar quem faz o Jornalismo. Nov. 2016. Disponível em:

$<$ https://medium.com/brio-stories/\%C3\%A9-preciso-valorizar-quem-faz-o-jornalismof7dc1aa0f61e\#.s3zh1pws0>. Acesso em: 17 nov. 2016.

Quem está à frente do BRIO?. Jun. 2015. Disponível em:

$\overline{<\mathrm{https}}$ ://medium.com/hist $\% \mathrm{C} 3 \% \mathrm{~B} 3$ rias-pra-frente/quem-est $\% \mathrm{C3} \% \mathrm{~A} 1-\% \mathrm{C} 3 \% \mathrm{~A} 0$-frente-dobrio-9672f988b6ef\#.18u9str0x>. Acesso em: 10 set. 2016.

Quem está por trás do BRIO?. Jun. 2015. Disponível em:

$<$ https://medium.com/hist\%C3\%B3rias-pra-frente/quem-est\%C3\%A1-por-tr\%C3\%A1s-do- 
brio-66e3f098f891\#.5i9j4ktoz>. Acesso em: 10 set. 2016.

. Mais uma janela para o jornalismo. Set. 2015. Disponível em:

$\overline{<\mathrm{https}}$ ://medium.com/hist\%C3\%B3rias-pra-frente/mais-uma-janela-para-o-jornalismod149bc3b2604\#.yjj46pg08>. Acesso em: 14 set. 2016.

. Razões para o otimismo com o jornalismo. Mar. 2016. Disponível em:

$<\mathrm{https}$ ://medium.com/brio-stories/raz\%C3\%B5es-para-otimismo-com-o-jornalismoe08aa023e85e\#.bpzqqk5b4>. Acesso em: 19 set. 2016.

Sigam imaginando. Jun. 2016. Disponível em: $<$ https://medium.com/brio-

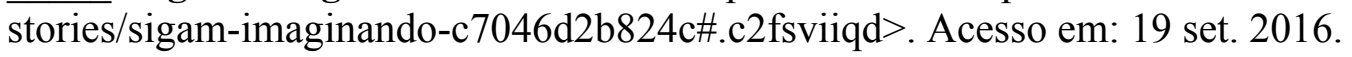

Vem tomar um café na nossa cozinha. Jul. 2015. Disponível em:

$\overline{<\mathrm{https}}$ ://medium.com/hist\%C3\%B3rias-pra-frente/vem-tomar-um-caf\%C3\%A9-na-nossacozinha-1a302fd0045b\#.gxonlgc3j>. Acesso em: 10 set. 2016.

COSTA, Caio Túlio. Um modelo de negócio para o jornalismo digital. Revista de Jornalismo Espm, São Paulo, ano 3, n. 9, p.51-115, abr./jun. 2014. Disponível em: $<$ http://caiotulio.com.br/2014/04/um-modelo-de-negocio-para-o-jornalismo-digital/>. Acesso em: 01 out. 2016.

CHIAVENATO, Idalberto. Empreendedorismo: dando asas ao espírito empreendedor e viabilização de novas empresas: um guia eficiente para iniciar e tocar seu próprio negócio. 2 . ed. São Paulo: Saraiva, 2007.

ENDEAVOR. Branding: qual a alma da sua empresa. E-book. 2014. Disponível em: $<$ http://info.endeavor.org.br/ebook-branding>. Acesso em: 15 nov. 2016.

EPIC MAGAZINE. What. About. Disponível em: <http://epicmagazine.com/\#about>. Acesso em: 10 nov. 2016.

FERRARI, Pollyana. Jornalismo digital. 3.ed. São Paulo: Contexto, 2008.

GIL, Antonio Carlos. Métodos e técnicas de pesquisa social. 6. ed. São Paulo: Atlas, 2008.

JÚNIOR, Carlos Pernisa; ALVES, Wedencley. Comunicação digital: jornalismo, narrativas, estética. Rio de Janeiro: Mauad X, 2010.

JÚNIOR, Célio Aparecido Rosa de Araújo, et al. Marca, o Elemento de Familiarização entre Cliente e Empresa. In: XXXVIII Congresso Brasileiro de Ciências da Comunicação, 2015, Rio de Janeiro. Anais. Intercom, 2015. p.1-15. Disponível em:

$<$ http://portalintercom.org.br/anais/nacional2015/resumos/R10-3259-1.pdf $>$. Acesso em: 08 out. 2016.

MICHAELIS. Definição de brio. Disponível em:

$<\mathrm{http}: / /$ michaelis.uol.com.br/busca?r=0\&f=0\&t=0\&palavra=brio $>$. Acesso em: 07 nov. 2016. 
OLIVEIRA, Andresa Caroline Lopes de; STIPP, Silvia Brandão Cuenca. Jornalismo Independente e novas narrativas: um olhar sob a série Amazônia Pública. In: XX

CONGRESSO DE CIÊNCIAS DA COMUNICAÇÃO NA REGIÃO SUDESTE, 2015, Uberlândia. Anais. Intercom, 2015. p.1-15. Disponível em:

$<$ http://www.portalintercom.org.br/anais/sudeste2015/resumos/R48-1257-1.pdf $>$. Acesso em: 11 maio 2016.

RAMOS, Daniela Osvald; SPINELLI, Egle Müller. Iniciativas de Jornalismo Independente no Brasil e Argentina. Extraprensa (USP), São Paulo, Ano IX, n. 17, p.114-123, jul./dez. 2015. Disponível em: <http://www.revistas.usp.br/extraprensa/article/view/104463/107438>. Acesso em: 04 maio 2016.

RIES, Eric. A startup enxuta: como os empreendedores atuais utilizam a inovação contínua para criar empresas extremamente bem-sucedidas. Tradução Texto Editores. São Paulo: Lua de Papel, 2012. Disponível em: <http://lelivros.pink/book/baixar-livro-a-startup-enxuta-ericries-em-pdf-epub-e-mobi/>. Acesso em: 06 out. 2015.

THE ATAVIST. Our story. About. Disponível em: $<$ https://atavist.com/page/about $>$. Acesso em: 10 nov. 2016.

ZOZZOLI, Jean Charles Jacques. A marca diante das novas práticas midiáticas. Pensamento e Realidade, São Paulo, v. 25, n. 2, p.11-30, 2010. Disponível em:

$<$ http://revistas.pucsp.br/index.php/pensamentorealidade/article/view/7230/5222>. Acesso em: 16 nov. 2016. 